\title{
RANCANG BANGUN DAN IMPLEMENTASI SISTEM PEMESANAN RUANG KELAS (SYSTEM BOOKING CLASS ONLINE)
}

\author{
Gerlan A. Manu ${ }^{1}$, \\ ${ }^{1}$ Sekolah Tinggi Keguruan dan Ilmu Pendidikan Citra Bina Nusantara \\ gerlanmanu@cbn.ac.id
}

\begin{abstract}
Abstrak
Tersedianya sarana dan prasarana dalam menunjang kegiatan pendidikan di Perguruan Tinggi diatur dalam UU No 20 tahun 2003 tentang Sistem Pendidikan Nasional pada pasal 45 ayat 1. Salah satu dari sarana dan prasarana di Perguruan Tinggi adalah ruangan kelas. Dengan meningkatnya jumlah mahasiswa di suatu Perguruan Tinggi maka perlu ketersediaan ruangan kelas yang cukup atau perlu adanya penambahan jumlah ruangan kelas di Perguruan Tinggi tersebut. Namun terkadang ruangan kelas yang tersedia di Perguruan Tinggi belum efektif digunakan. Oleh karena itu perlu adanya suatu manajemen ruangan kelas yang baik. Dalam penelitian ini dibuat Rancang Bangun System Booking Class Online yang kemudian diimplementasikan di Yayasan Citra Bina Nusantara pada tahun ajaran 2017/2018 semester genap. Yayasan Citra Bina Nusantara memiliki dua Sekolah Tinggi yaitu STIKES CHMK dan STKIP CBN, dan menghadapi permasalahan dalam manajemen ruangan kelas. Dari kedua Sekolah Tinggi tersebut meminta untuk adanya penambahan ruangan kelas baru, namun kenyataan di lapangan penggunaan kelas masih belum efektif. Terdapat beberapa kelas yang kosong namun terjadwalkan. Berdasarkan implementasi sistem pada semester genap tahun ajaran 2017/2018 diperoleh manajemen ruangan kelas dapat dilaksanakan secara efektif dan diperoleh data penggunaan kelas oleh masing-masing program studi. Dengan data tersebut Yayasan dapat mengambil kebijakan untuk melakukan penambahan sejumlah ruangan kelas yang dibutuhkan atau tidak melakukan penambahan ruangan kelas.
\end{abstract}

Kata Kunci : Sistem Informasi, Perancangan System, Sistem Pemesanan Ruangan Kelas, Booking Class

\section{PENDAHULUAN}

Berdasarkan UU No 20 Tahun 2003 tentang Sistem Pendidikan Nasional Pasal 45 Ayat 1, maka Perguruan Tinggi sebagai salah satu satuan pendidikan formal wajib menyediakan sarana dan prasarana untuk menunjang kegiatan pendidikan yang dilaksanakan [6]. Salah satu dari sarana dan prasarana di Perguruan Tinggi adalah ruangan kelas. Dengan meningkatnya jumlah mahasiswa mempengaruhi kebutuhan akan ruangan kelas dan hal ini menjadi salah satu permasalah teknis yang sering terjadi pada bagian akademik dan bagian sarana prasarana di Perguruan Tinggi.

Pada Yayasan Citra Bina Insan Mandiri memiliki dua sekolah tinggi, yaitu Stikes CHMK dan Stkip CBN. Kedua sekolah tinggi tersebut menggunakan satu gedung rektorat yang terbagi atas lima lantai, terdiri dari 34 ruangan kelas, 1 Aula Besar, dan 1 Aula Kecil dan beberapa ruangan kantor. Total jumlah mahasiswa Stikes CHMK pada tahun ajaran 2016/2017 berjumlah 276 mahasiswa dan pada tahun ajaran 2017/2018 berjumlah 322 mahasiswa. Sedangkan total jumlah mahasiswa Stkip CBN pada tahun ajaran 2016/2017 berjumlah 101 mahasiswa dan pada tahun ajaran 2017/2018 berjumlah 74 mahasiswa. Dengan total mahasiswa yang ada maka penggunaan ruangan kelas menjadi permasalahan setiap semesternya dalam penjadwalan kuliah. Stikes CHMK memiliki 3 program studi dengan kebutuhan kelas sejumlah 25 kelas dan Stkip CBN memiliki 3 program studi dengan kebutuhan kelas sejumlah 7 kelas, jauh lebih sedikit dibanding 
Stikes CHMK karena masih baru sehingga belum banyak memiliki mahasiswa.

Manajemen merupakan proses perencanaan, pengorganisasian, pemimpinan, dan pengawasan dalam rangka untuk mencapai tujuan yang ditetapkan [1]. Manajemen penggunaan ruangan kelas yang dijalankan secara cermat dan sistematis dapat membantu proses alokasi ruangan kelas yang efektif. Dalam pemanfaatan ruangan kelas terdapat ruangan yang sudah terjadwalkan namun tidak digunakan, dikarenakan adanya kesibukan dosen sehingga perkuliahan ditunda dan kelas menjadi kosong. Disamping itu terdapat beberapa permasalahan lainnya dalam penggunaan kelas, seperti adanya ruangan kelas yang terjadwalan untuk suatu matakuliah praktek, dan pada waktu dan hari yang sama di laboratorium juga terjadwalkan matakuliah tersebut. Hal ini dinilai tidak efisiennya penggunaan kelas yang tersedia.

Untuk mengatasinya maka perlu adanya suatu manajemen ruangan kelas yang terpadu bagi kedua sekolah tinggi yang berada dinaungan Yayasan Citra Bina Insan Mandiri. Dalam mewujudkan manajemen ruangan kelas tersebut Yayasan Citra Bina Insan Mandiri memerlukan suatu sistem informasi. Sistem informasi merupakan suatu sistem didalam suatu organisasi yang mempertemukan kebutuhan pengelolaan transaksi harian, mendukung operasi, bersifat manejerial dan kegiatan strategis dari suatu organisasi [2]. Dengan demikian dalam hal manajemen ruangan kelas dibuatlah System Booking Class Online.

Dengan sistem ini, maka penggunaan ruangan kelas menjadi lebih efektif. Setiap program studi dari kedua sekolah tinggi dapat melakukan pemesanan kelas secara online, dan Yayasan dapat memantau secara langsung penggunaan kelas tersebut. Dengan manajemen ruangan kelas menggunakan sistem ini maka akan terdata penggunaan kelas secara efektif oleh setiap pengguna ruangan yang ada, dan dengan data tersebut jika diperlukan, Yayasan dapat berupaya untuk pembangunan ruangan kelas tambahan.

\section{METODE PENELITIAN}

Dalam siklus hidup pengembangan sistem (System Development Life Cycle SDLC), terdapat beberapa metodologi yang membentuk suatu kerangka kerja untuk perencanaan dan pengendalian pembuatan sistem informasi [4]. Metodologi pengembangan System Booking Class Online dalam penelitian ini adalah sebagai berikut :

1. Analisa, Desain dan Perancangan Sistem

2. Pembuatan Sistem

3. Dokumentasi dan Implementasi

\section{HASIL DAN PEMBAHASAN Analisa dan Perancangan Sistem}

Sebelum melakukan perancangan sistem, dilakukan analisa kebutuhan sistem. Berikut adalah hasil analisa kebutuhan sistem:

1. Pendataan pengguna sistem.

2. Pendataan Program Studi.

3. Pendataan ruangan yang dapat dilakukan pemesanan.

4. Pendataan dan penyeragaman periode waktu penggunaan ruangan kelas.

5. Pendataan Liburan Nasional.

6. Prosedur penggunaan ruangan.

Berdasarkan hasil analisa kebutuhan maka, dapat dirancang desain sistem dengan menggunakan standar pemodelan sistem menggunakam UML (Unifed Modelling Language) [5], yang terdiri dari :

1. Use Case Diagram

2. Activity Diagram

3. Sequence Diagram dan

4. Class Diagram

Untuk perancangan basis data (database) sistem menggunakan ERD (Entity Relationship Diagram).

\section{Use Case Diagram}

Pada Use Case Diagram ini, terdapat dua Actor yaitu Admin dan Prodi. Admin memiliki hak akses untuk melakukan manajemen pengguna, manajemen ruang, manajemen program studi, manajemen libur nasional, manajemen periode waktu, View 
Booking, Single Booking, Multi Booking dan Cancel Booking.

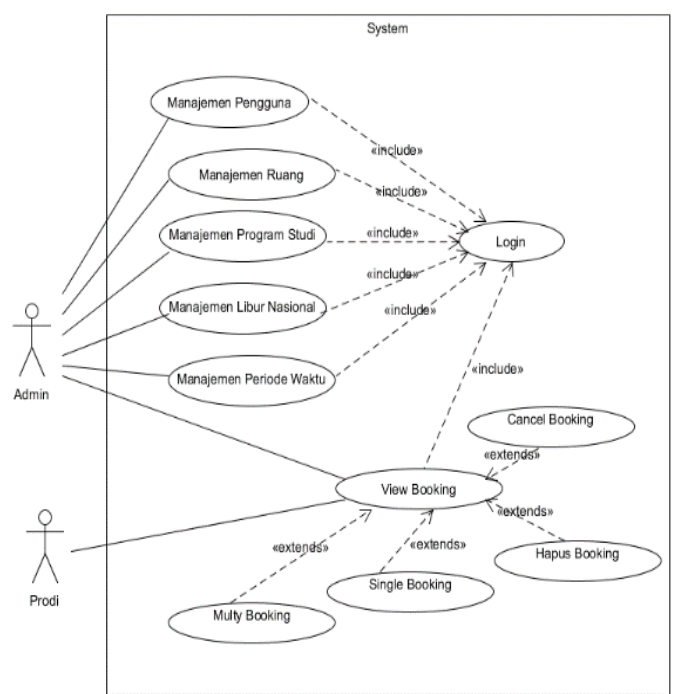

Gambar 1. Use Case Diagram

Prodi memiliki hak akses untuk melakukan View Booking, Single Booking, Multi Booking dan Cancel Booking.

\section{Activity Diagram}

Activity Diagram ini adalah diagram yang menggambarkan aktivitas dari System Booking Class Online atau worlflow (aliran kerja) atau proses bisnis dari sistem ini. Activity Diagram yang digambarkan dari sistem ini adalah Activity Diagram Login, Activity Diagram Manajemen Pengguna, Activity Diagram Program Studi, Activity Diagram Libur Nasional, Activity Diagram Periode Waktu, Activity Diagram Manajemen View Booking. Untuk lebih jelasnya dapat dilihat pada gambar 2 hingga gambar 8 dibawah ini.

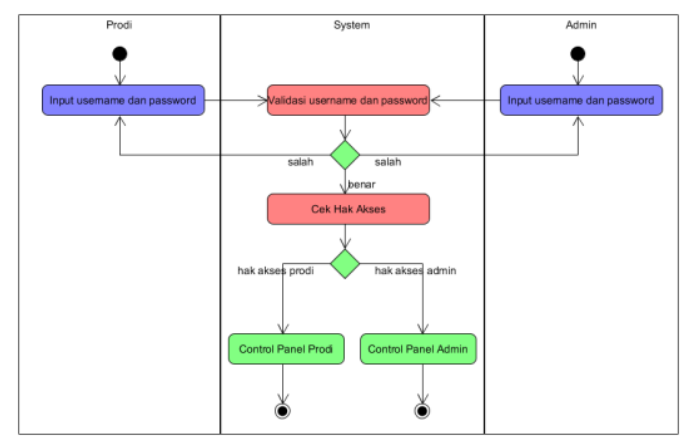

Gambar 2. Activy Diagram - Login
Pada Activity Diagram Login, untuk dapat masuk ke dalam sistem pengguna memerlukan username dan password. Khusus untuk Prodi, username dan passwordnya dibuatkan oleh administrator.

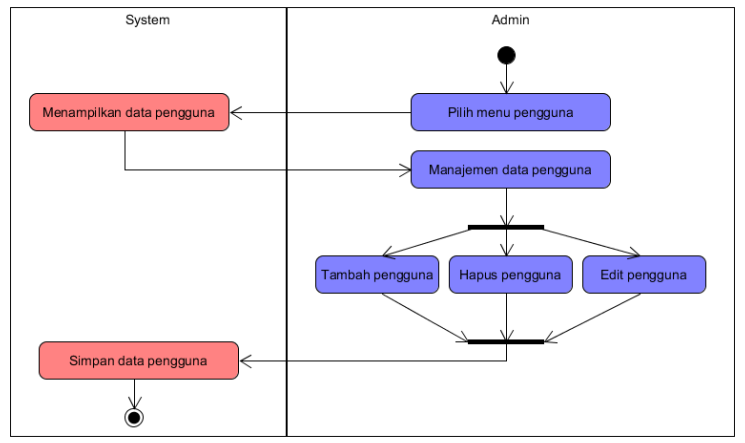

Gambar 3. Activy Diagram - Manajemen Pengguna

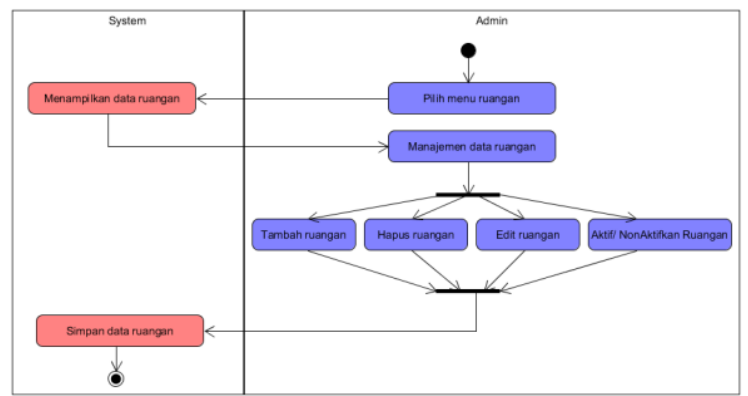

Gambar 4. Activy Diagram - Manajemen Ruang

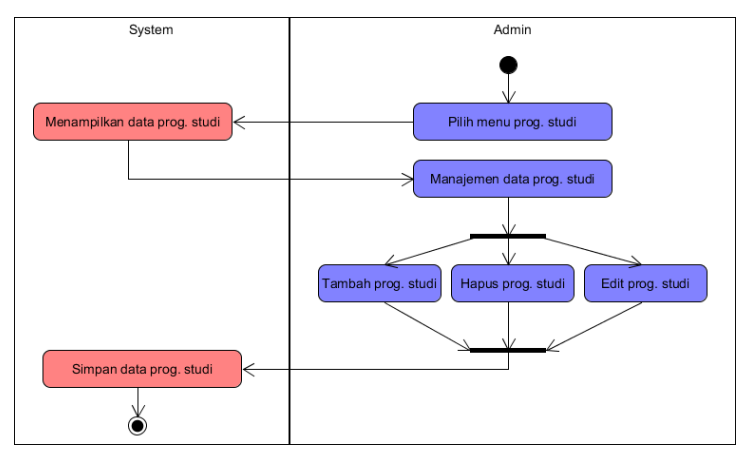

Gambar 5. Activy Diagram - Manajemen Program Studi

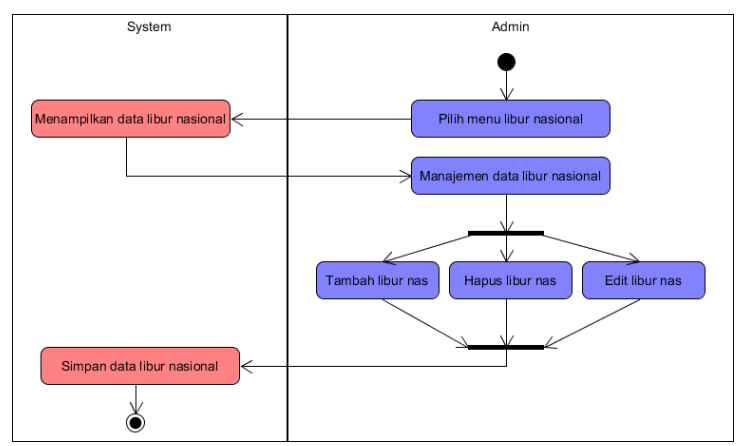

Gambar 6. Activy Diagram - Manajemen Libur Nasional 


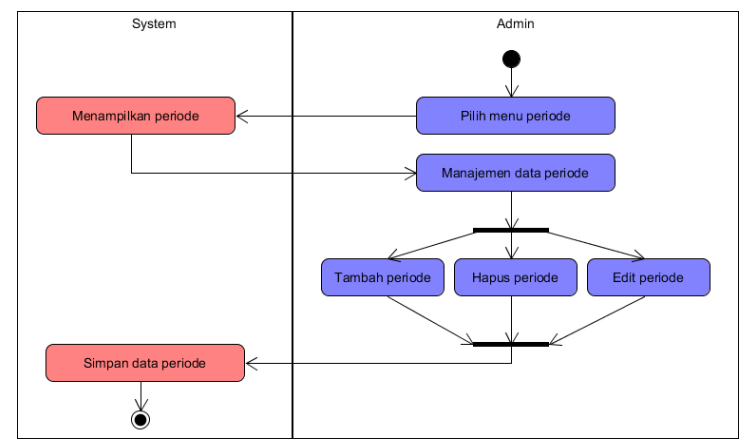

Gambar 7. Activy Diagram - Manajemen Periode Waktu

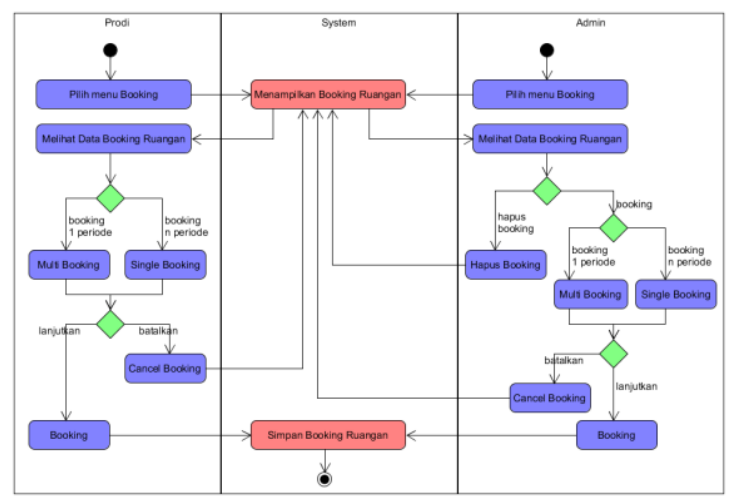

Gambar 8. Activy Diagram - Manajemen View Booking

Pada Activity Diagram - Manajemen View Booking, dapat dilihat proses bisnis sistemnya. Dimana terdapat dua cara booking, yaitu Multi Booking dan Single Booking.

\section{Entity Relationship Diagram}

Entity Relationship (E-R) Model adalah representasi grafis dari logika database dengan menyertakan deksripsi detail mengenai seluruh entitas (entity), hubungan (relationship) dan batasan (constraint). Diagram E-R merupakan kunci untuk memahami dan membuat desain sebuah database [3]. Berikut adalah Diagram ER dari System Booking Class Online :

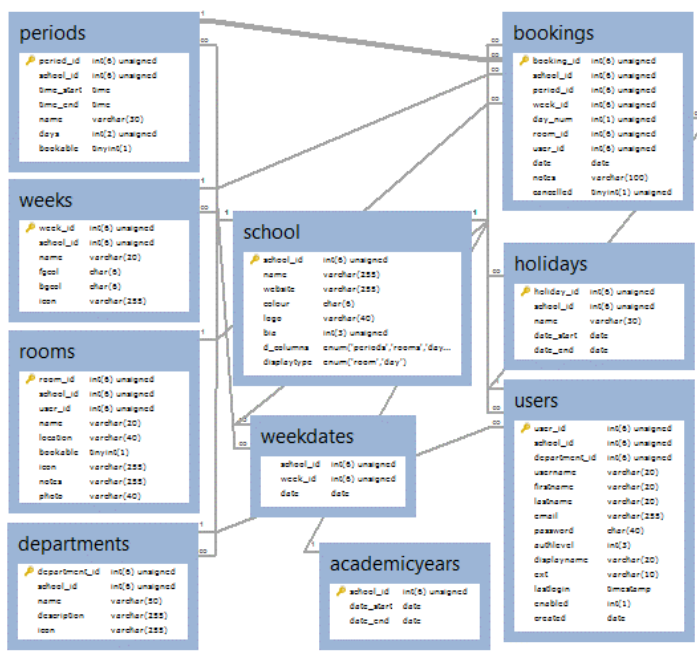

Gambar 9. Entity Relationship Diagram

\section{Implementasi Sistem}

Berdasarkan Desain dan Perancangan Sistem menggunakan UML (Unifed Modelling Language) dan Perancangan Database menggunakan ERD (Entity Relationship Diagram) maka dibuatlah System Booking Class Online menggunakan framework Codeigniter (CI) dan dihostingkan, agar dapat diakses secara online oleh pengguna sistem. System Booking Class Online dilaunching pada awal semester genap tahun ajaran 2017/2018 dan dapat diakses pada laman http://cbim.or.id/booking. Setelah pembuatan sistem dan uji coba sistem selanjutnya dalam penelitian ini disusun dokumentasi pemeliharaan sistem, dan penggunaan sistem. Agar sistem dapat terus diperbaharui jika dikemudian hari ditemukan bug atau terdapat penambahan fitur/content.

Para pengguna sistem ini adalah petugas penjadwalan di program studi yang berasal dari dua sekolah tinggi dibawah naungan Yayasan CBIM yaitu STIKES CHMK dan STKIP CBN. Program studi tersebut adalah dari Prodi Ners, Prodi Kebidanan, Prodi Farmasi, Prodi Pend Informatika, Prodi Pend Bahasa Inggris, dan Prodi PGSD. 


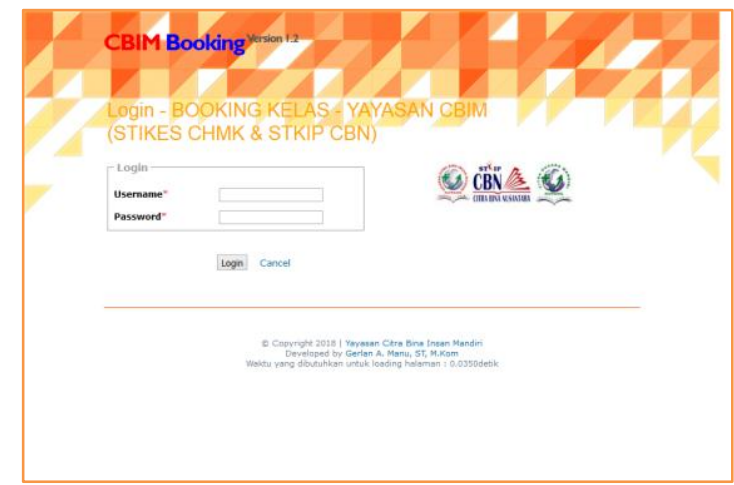

Gambar 10. Tampilan Halaman Login

Masing-masing petugas penjadwalan dari setiap program studi akan dibuatkan akun untuk dapat login ke sistem. Selain petugas penjadwalan juga tersedia akun dari pihak Yayasan untuk memantau penggunaan sistem. Berikut adalah tampilan halaman user pada System Booking Class Online :

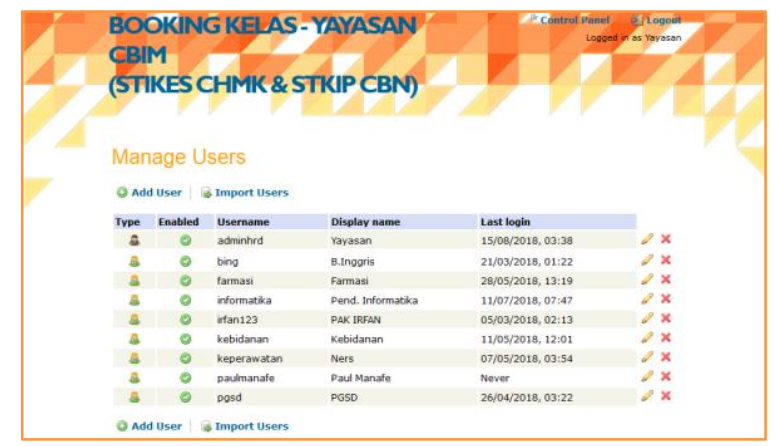

Gambar 11. Tampilan Halaman User

Setiap akun yang telah terdaftar dapat menggantikan password mereka masingmasing. Berikut adalah tampilan halaman edit user :

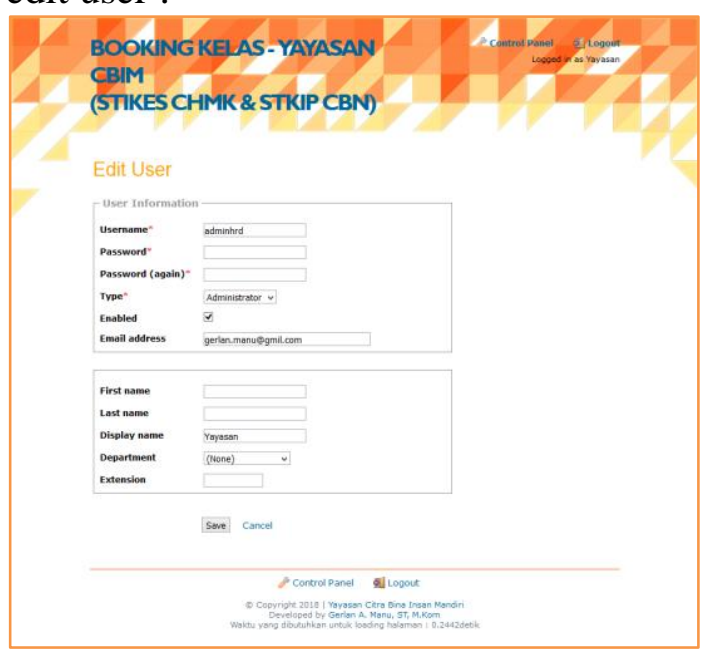

Gambar 12. Tampilan Halaman Edit User
Proses Booking ruangan dapat dilakukan setelah administrator sistem melakukan beberapa pengaturan, seperti :

1. Pengaturan Ruangan, agar pengguna sistem dapat melakukan booking ruangan maka perlu adanya data ruangan.

2. Pengaturan tanggal mulai dan tanggal akhir yang menandakan dimulainya suatu semester pada tahun ajaran tertentu.

3. Pengaturan Periode Jadwal. Setelah pengaturan tahun ajaran, dilanjutkan dengan memasukan data periode jadwal. Periode jadwal mendata pembagian waktu perkuliahan, dimulai dari jam pertama hingga selesai. Berdasarkan hasil analisa kebutuhan sistem pada kedua Sekolah Tinggi di Yayasan CBIM ini rata-rata perkuliahan dimulai pada pukul 06.30 dan paling lambat selesai pukul 19.00. Maka dimasukkan periode jadwalnya dengan durasi 1 jam. Sehingga jam pertama adalah pukul $06.00 \mathrm{~s} / \mathrm{d} 07.00$ dan seterusnya hingga selesai pada pukul 19.00. Dengan pembagian periode seperti ini dapat terpantau pemakaian ruangan per jam pada setiap ruangan yang tersedia. Berikut adalah tampilan halaman periode jadwal.

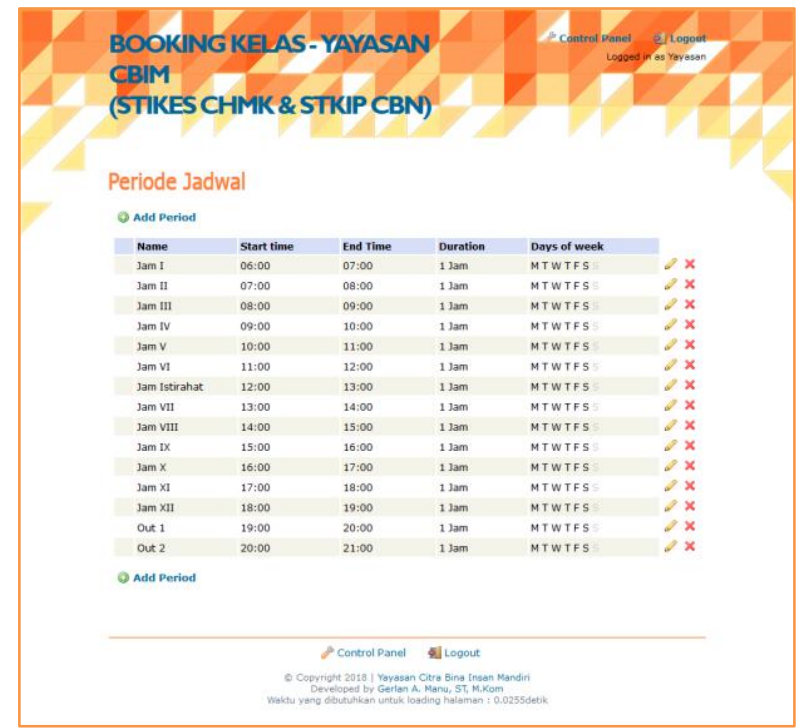

Gambar 13. Tampilan Halaman Periode Jadwal 
e-ISSN : 2621-1467

Setelah administrator sistem melakukan beberapa pengaturan sistem tersebut, maka sistem siap digunakan oleh program studi. Dalam proses Booking ruangan, program studi dapat melakukan pemesanan ruangan dengan dua cara yaitu :

1. Single Booking

2. Multi Booking

Single Booking dilakukan jika Program Studi memerlukan ruangan untuk kegiatan yang hanya berada pada satu periode. Misalnya kegiatan pada pukul 06.00 s.d 07.00, maka bisa dilakukan booking dengan cara Single Booking.

Multi Booking dilakukan jika Program Studi memerlukan ruangan untuk kegiatan yang berada pada lebih dari satu periode. Misalnya suatu mata kuliah tertentu dijadwalkan pada pukul $06.30 \mathrm{~s} / \mathrm{d}$ 09.30, maka bisa dilakukan booking dengan cara Multi Booking, yaitu mencentang pada periode jadwal pertama, hingga keempat.

Untuk Single Booking tersedia kolom centang untuk Recurring Options atau pengulangan mingguan. Kolom ini dicentang jika kegiatan pada ruangan kelas yang dipesan akan berulang setiap minggunya selama tahun ajaran berlangsung. Sedangkan untuk Multi Booking sudah otomatis akan berulang setiap minggunya. Sehingga untuk proses booking ruangan dengan cara Multi Booking dikhususkan untuk penjadwalan mata kuliah yang sifatnya tetap.

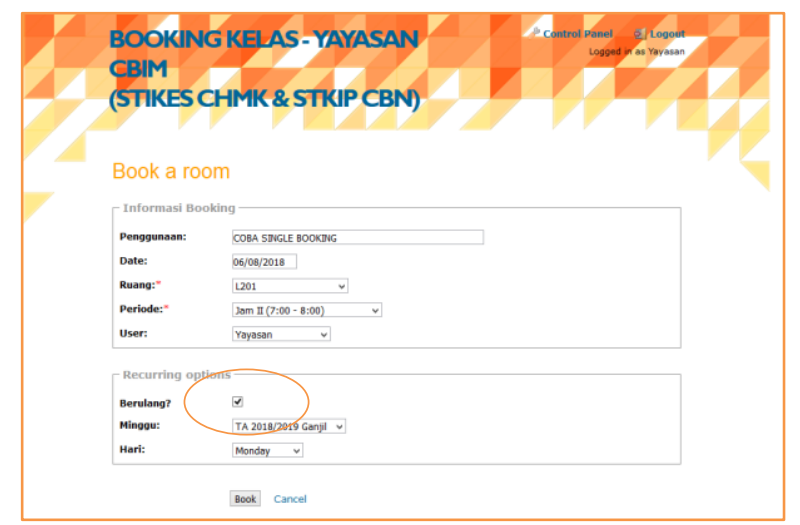

Gambar 13. Tampilan Halaman Booking Ruangan - Single Booking

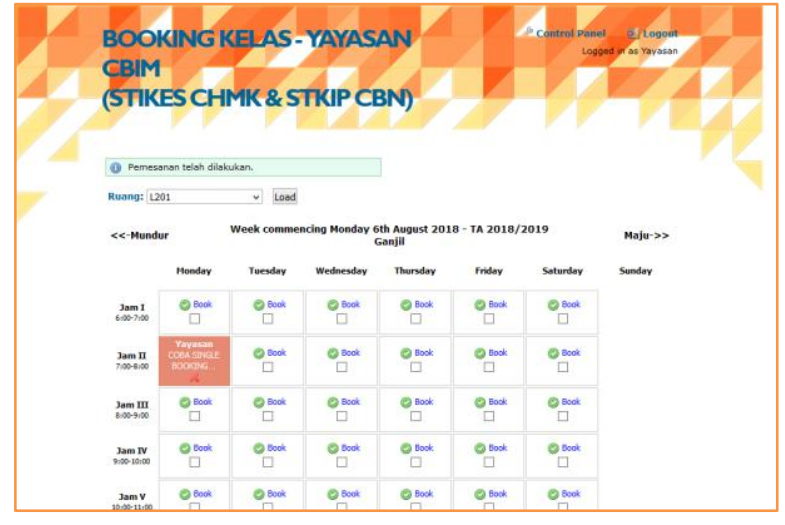

Gambar 14. Tampilan Halaman Booking untuk Ruangan L201 setelah uji coba single booking

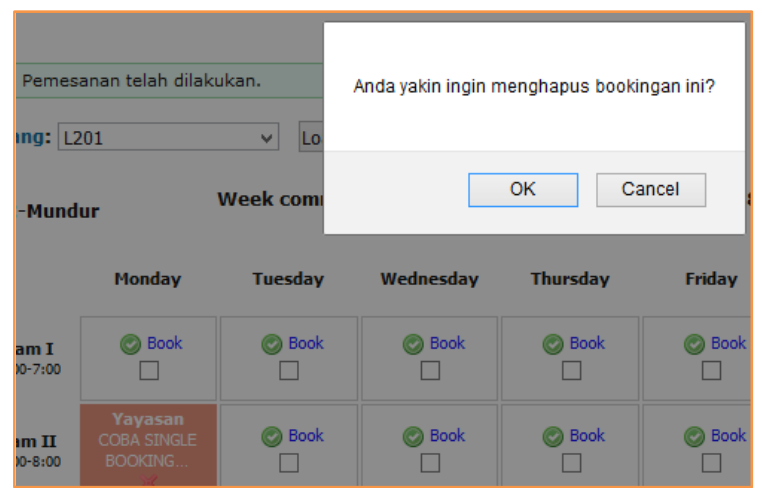

Gambar 15. Tampilan Hapus Booking

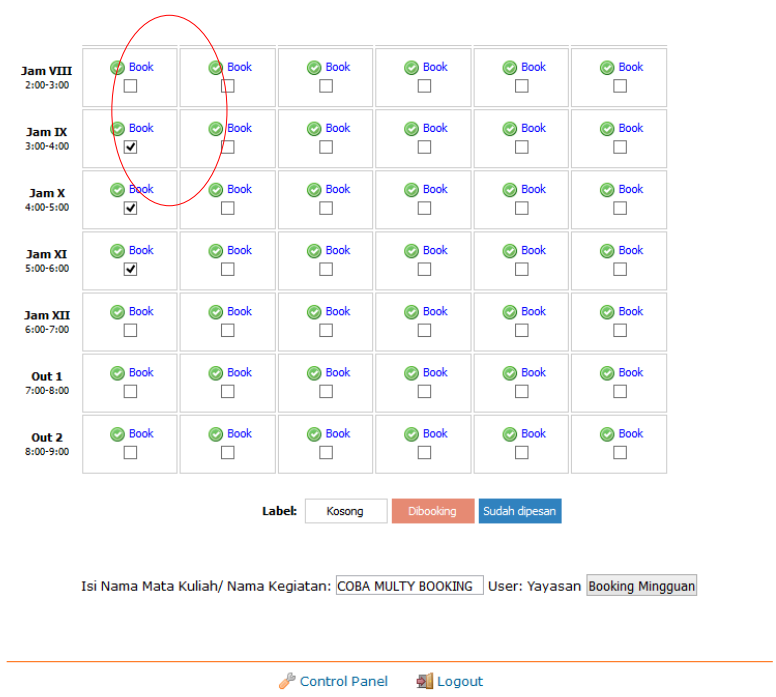

Gambar 16. Tampilan Halaman Booking Ruangan - Multi Booking 


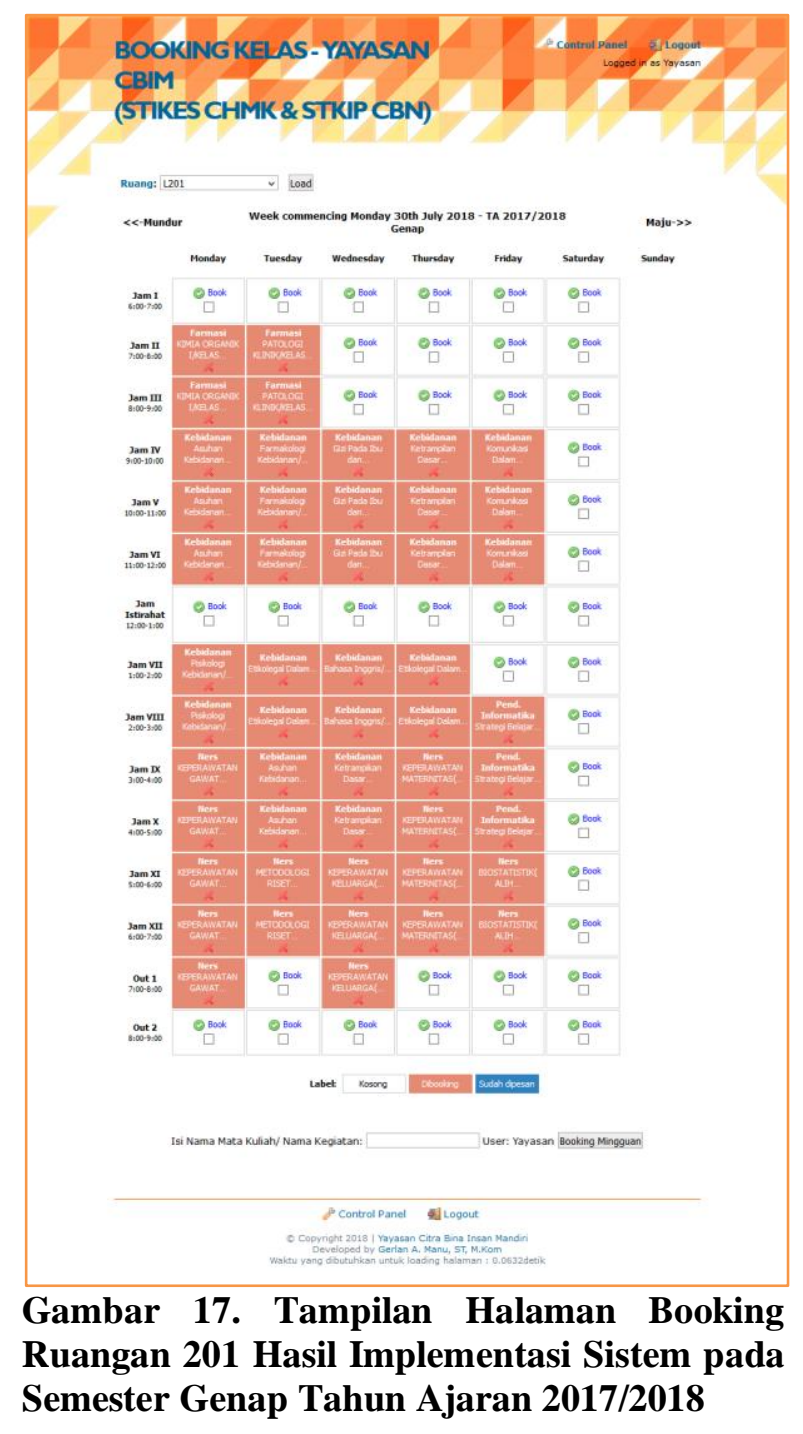

\section{KESIMPULAN}

Berdasarkan penelitian yang dilakukan maka dapat disimpulkan beberapa hal sebagai berikut :

1. Dengan adanya System Booking Class Online ini manajemen ruangan kelas dapat dilakukan dengan efektif dan efisian.

2. System Booking Class Online mempermudah pimpinan dalam mengambil kebijakan.

\section{DAFTAR PUSTAKA}

[1] Gaol, L, Jimmy. Sistem Informasi Manajemen Pemahaman dan Aplikasi. Jakarta : Penerbit PT Grasindo. 2008.
[2] Hutahaean Jeperson. Konsep Sistem Informasi. Yogyakarta : Penerbit Deepublish. 2014.

[3] Kadir Abdul. Konsep \& Tuntunan Praktis Basis Data. Yogyakarta : Penerbit ANDI. 2002.

[4] Mulyani Sri. Metode Analisis dan Perancangan Sistem. Bandung : Penerbit Abdi Sistematika. 2016.

[5] Nugroho Adi. Rekayasa Perangkat Lunak Menggunakan UML dan Java. Yogyakarta : Penerbit ANDI. 2009.

[6] Undang-Undang Republik Indonesia Nomor 20 Tahun 2003 Sistem Pendidikan Nasional. Jakarta : Lembaran Negara Republik Indonesia Tahun 2003 Nomor 4301. 8 Juli 2003. 